\title{
How Do We Bridge the West and the East in the Treatment for Gastric Cancer?
}

\author{
Koichi Suda, MD, PhD, FACS and Yuko Kitagawa, MD, PhD, FACS \\ Cancer Center/Department of Surgery, School of Medicine, Keio University, Tokyo, Japan
}

In 2012, gastric cancer (GC) was the fifth most common malignancy and the third leading cause of cancer death in the world. ${ }^{1}$ The prevalence of GC remains more common in countries of the Far East, including Japan and Korea, than in countries of the West. ${ }^{2}$ Moreover, better overall survival (OS) has been reported in Eastern trials than the Western series (East vs West 5-year OS: 60-70 vs $30-40 \%)^{3-7}$ Eastern investigators may argue that this difference is attributable to more radical surgery, whereas Western investigators may claim that this difference is attributable to earlier detection and differences in biology. 8,9

Recently, Ikoma et al. ${ }^{10,11}$ at MD Anderson Cancer Center, in which the standard extent of lymph node dissection has been D2, reported the factors contributing to lymph node metastasis and the 5-year OS of patients with pathologic stage $\mathrm{T} 1$ or $\mathrm{T} 2 \mathrm{GC}$. In their single-institution retrospective study, 122 patients with $\mathrm{T} 1$ or $\mathrm{T} 2 \mathrm{GC}$ who underwent R0 resection without preoperative treatment were examined. ${ }^{10,11}$ Extended lymph node dissection (D1 +/D2) was performed for $55 \%$ of the patients. ${ }^{11}$ As a result, race, T1b stage or higher, and 15 or more lymph nodes examined were risk factors for lymph node metastasis, ${ }^{10}$ whereas T2 stage, but not race or nodal status, was the only variable independently associated with 5-year OS. ${ }^{11}$ The lymph node metastasis rates were $10 \%$ for stage T1a, $34 \%$ for stage T1b, and $44 \%$ for stage T2 tumor. ${ }^{10}$ The 5-year OS was $98 \%$ for stage T1a, $93 \%$ for stage T1b, and $66 \%$ for stage T2 tumors. ${ }^{11}$ Collectively, surgical resection with locoregional lymph node dissection mostly

\section{(C) Society of Surgical Oncology 2016}

First Received: 3 September 2016;

Published Online: 25 October 2016

K. Suda, MD, PhD, FACS

e-mail: ko-suda@nifty.com cured early GC, although the rates for lymph node metastasis were higher for each $\mathrm{T}$ stage than those found in reports from Asia. ${ }^{10,11}$ Although their study had a couple of limitations, including its retrospective design and relatively small sample due to their preference for preoperative therapy used for $\mathrm{T} 2$ stage or higher, $\mathrm{N}+$ tumor, or both ${ }^{10,11}$ these outcomes suggest that indications for endoscopic resection (ER) should be more confined, at least in their region than in Japan, in which ER has been extensively indicated for early GC.

In reality, many clear differences that may account for better long-term outcomes in the East than in the West exist, namely, earlier detection of GC because of mass cancer screening programs based on higher incidence, ${ }^{12}$ pathologic evaluation focused more on nuclear cytologic and glandular architecture abnormalities, ${ }^{13-15}$ tumor biology including more distal location as well as more differentiated histology, ${ }^{9}$ wider adoption of ER for early GC and D2 lymphadenectomy for advanced GC, ${ }^{8,9}$ and less frequent use of preoperative chemotherapy. ${ }^{16}$ However, because Japanese and Korean physicians have been building a therapeutic algorithm for the treatment for $\mathrm{GC}^{17}$ over time according to their abundant experience and evidence based on their high quality of patho$\operatorname{logic}^{13-15}$ and endoscopic ${ }^{18}$ diagnosis combined with that of endoscopic and surgical treatment, including ER and D2 dissection, ${ }^{9,16,19}$ it may be good for Western physicians to create their own therapeutic algorithm based on the Eastern high quality of diagnostic and therapeutic methods, taking into account the characteristics of the region, including race. ${ }^{10}$

In conclusion, active discussion, communication, and collaboration between Western and Eastern endoscopists, pathologists, surgeons, and medical oncologists, particularly in terms of diagnostic and therapeutic methods, must be the key to bridging the West and the East in the treatment for GC. 
DISCLOSURE This work was not supported by any grants or funding. K. S. and Y. K. have no commercial association with or financial involvement that might pose a conflict of interest in connection with the submitted article.

\section{REFERENCES}

1. Ferlay J, Soerjomataram I, Dikshit R, et al. Cancer incidence and mortality worldwide: sources, methods, and major patterns in GLOBOCAN 2012. Int J Cancer. 2015;136:E359-86.

2. Kamangar F, Dores GM, Anderson WF. Patterns of cancer incidence, mortality, and prevalence across five continents: defining priorities to reduce cancer disparities in different geographic regions of the world. J Clin Oncol. 2006;24:2137-50.

3. Sasako M, Sakuramoto S, Katai H, et al. Five-year outcomes of a randomized phase III trial comparing adjuvant chemotherapy with S-1 versus surgery alone in stage II or III gastric cancer. $J$ Clin Oncol. 2011;29:4387-93.

4. Sakuramoto S, Sasako M, Yamaguchi T, et al. Adjuvant chemotherapy for gastric cancer with S-1, an oral fluoropyrimidine. N Engl J Med. 2007;357:1810-20.

5. Nashimoto A, Nakajima T, Furukawa H, et al. Randomized trial of adjuvant chemotherapy with mitomycin, fluorouracil, and cytosine arabinoside followed by oral fluorouracil in serosanegative gastric cancer: Japan Clinical Oncology Group 9206-1. J Clin Oncol. 2003;21:2282-7.

6. Macdonald JS, Smalley SR, Benedetti J, et al. Chemoradiotherapy after surgery compared with surgery alone for adenocarcinoma of the stomach or gastroesophageal junction. $N$ Engl J Med. 2001;345:725-30.

7. Cunningham D, Allum WH, Stenning SP, et al. Perioperative chemotherapy versus surgery alone for resectable gastroesophageal cancer. N Engl J Med. 2006;355:11-20.

8. Markar SR, Karthikesalingam A, Jackson D, Hanna GB. Longterm survival after gastrectomy for cancer in randomized, controlled oncological trials: comparison between West and East. Ann Surg Oncol. 2013;20:2328-38.

9. Yamamoto M, Rashid OM, Wong J. Surgical management of gastric cancer: the East vs. West perspective. J Gastrointest Oncol. 2015;6:79-88.

10. Ikoma N, Blum M, Chiang YJ, et al. Race is a risk for lymph node metastasis in patients with gastric cancer. Annals of Surgical Oncology. New York; Springer; 2016, vol 23, p. S177

11. Ikoma N, Blum M, Chiang YJ, et al. Survival rates in T1 and T2 gastric cancer: a Western report. J Surg Oncol. 2016. doi:10. 1002/jso. 24382.

12. Choi IJ. Endoscopic gastric cancer screening and surveillance in high-risk groups. Clin Endosc. 2014;47:497-503.

13. Schlemper RJ, Itabashi M, Kato Y, et al. Differences in diagnostic criteria for gastric carcinoma between Japanese and western pathologists. Lancet. 1997;349:1725-9.

14. Willis J, Riddell RH. Biology versus terminology: East meets West in surgical pathology. Gastrointest Endosc. 2003;57:369-76.

15. Lauwers GY, Shimizu M, Correa P, et al. Evaluation of gastric biopsies for neoplasia: differences between Japanese and Western pathologists. Am J Surg Pathol. 1999;23:511-8.

16. Van Cutsem E, Dicato M, Geva R, et al. The diagnosis and management of gastric cancer: expert discussion and recommendations from the 12th ESMO/World Congress on Gastrointestinal Cancer, Barcelona, 2010. Ann Oncol. 2011;22(Suppl 5):v1-9.

17. Japanese Gastric Cancer Association (2016) Japanese gastric cancer treatment guidelines 2014. version 4. Gastric Cancer. doi:10.1007/s10120-016-0622-4.

18. Kaise M, Kato M, Tajiri H. High-definition endoscopy and magnifying endoscopy combined with narrow band imaging in gastric cancer. Gastroenterol Clin North Am. 2010;39:771-84.

19. Gotoda T, Ho KY, Soetikno R, Kaltenbach T, Draganov P. Gastric ESD: current status and future directions of devices and training. Gastrointest Endosc Clin North Am. 2014;24:213-33. 